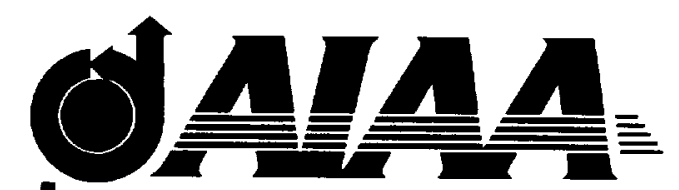

AIAA 2000-4006

Aerodynamic Database Development for the Hyper-X Airframe Integrated Scramjet Propulsion Experiments

Walter $\mathrm{C}$. Engelund,

Scott D. Holland,

Charles E. Cockrell, Jr.

NASA Langley Research Center

Hampton, VA

Robert D. Bittner

FDC-NYMA, Inc.

Hampton, VA

AIAA 18th Applied Aerodynamics Conference

August 14-17, 2000

Denver, Colorado

For permission to copy or republish, contact the American Institue of Aeronautics and Astronautics, 1801 Alexander Bell Drive, Suite 500, Reston, VA 20191-4344 


\title{
AERODYNAMIC DATABASE DEVELOPMENT FOR THE HYPER-X AIRFRAME INTEGRATED SCRAMJET PROPULSION EXPERIMENTS
}

\author{
Walter C. Engelund, ${ }^{*}$ Scott D. Holland, ${ }^{* *}$ Charles E. Cockrell, Jr. ${ }^{+}$ \\ NASA Langley Research Center \\ and \\ Robert D. Bittner $\ddagger$ \\ FDC-NYMA, Inc., Hampton, VA
}

\begin{abstract}
This paper provides an overview of the activities associated with the aerodynamic database which is being developed in support of NASA's Hyper-X scramjet flight experiments. Three flight tests are planned as part of the Hyper-X program. Each will utilize a small, nonrecoverable research vehicle with an airframe integrated scramjet propulsion engine. The research vehicles will be individually rocket boosted to the scramjet engine test points at Mach 7 and Mach 10. The research vehicles will then separate from the first stage booster vehicle and the scramjet engine test will be conducted prior to the terminal decent phase of the flight. An overview is provided of the activities associated with the development of the Hyper- $\mathrm{X}$ aerodynamic database, including wind tunnel test activities and parallel CFD analysis efforts for all phases of the Hyper-X flight tests. A brief summary of the Hyper-X research vehicle aerodynamic characteristics is provided, including the direct and indirect effects of the airframe integrated scramjet propulsion system operation on the basic airframe stability and control characteristics. Brief comments on the planned post flight data analysis efforts are also included.
\end{abstract}

\section{Nomenclature}

$\alpha \quad$ angle-of-attack (degrees)

$\beta \quad$ angle-of-sideslip (degrees)

- Vehicle Analysis Branch, Senior Member AIAA

"Assistant Branch Head, Aerothermodynamics Branch, Senior Member AIAA.

${ }^{\dagger}$ Hypersonic Airbreathing Propulsion Branch, Senior Member AIAA.

${ }_{+}^{+}$Hypersonic Numerical Applications Group, Hyper-XProgram Office.

Copyright 02000 American Institute of Aeronautics and Astronautics, Inc. No copyright is asserted in the United States under Title 17, U.S. Code. The U.S. Government has a royalty-free license to exercise all rights under the copyright claimed herein for Governmental purposes. All other rights are reserved by the copyright owner. $b_{\text {ref }}$ Hyper- $X$ vehicle reference span

$\mathrm{C}_{\mathrm{D}} \quad$ Drag force coefficient $\left(\frac{\text { drag }}{q_{\infty} S_{r e f}}\right)$

$\mathrm{C}_{\mathrm{L}} \quad$ Lift force coefficient $\left(\frac{\text { lift }}{q_{\infty} S_{r e f}}\right)$

$\mathrm{C}_{1} \quad$ Rolling moment coefficient $\left(\frac{\text { rolling moment }}{q_{\infty} S_{r e f} b_{r e f}}\right)$

$\mathrm{C}_{\mathrm{I}_{\mathrm{a}}} \quad$ Rolling moment coefficient derivative due to aileron deflection (per degree)

$\mathrm{C}_{\mathrm{l}_{\beta}} \quad$ Rolling moment coefficient derivative with respect to sideslip angle

$\mathrm{C}_{\mathrm{m}} \quad$ Pitching moment coefficient $\left(\frac{\text { pitching moment }}{q_{\infty} S_{\text {ref }} l_{\text {ref }}}\right)$

$\mathrm{C}_{\mathrm{n}} \quad$ Yawing moment coefficient $\left(\frac{\text { yawing moment }}{q_{\infty} S_{r e f} b_{r e f}}\right)$

$C_{n_{\beta}} \quad$ Yawing moment coefficient derivative with respect to sideslip angle

$\mathrm{C}_{\mathrm{n}} \quad$ Yawing moment coefficient derivative due to aileron deflection (per degree)

$\mathrm{C}_{\mathrm{Y}} \quad$ Side force coefficient $\left(\frac{\text { side force }}{q_{\infty} S_{\text {ref }}}\right)$

$C_{Y_{\beta}}$ Side force coefficient derivative with respect to sideslip angle

$\mathrm{C}_{\mathrm{Y}_{\delta \mathrm{a}}}$ Side force coefficient derivative due to aileron deflection (per degree)

$\delta_{\mathrm{a}} \quad$ aileron deflection (differential horizontal tail: $\left.\delta_{r w}-\delta_{l w^{\prime}}\right)$, degrees

$\delta_{\text {elv }}$ elevator deflection (symmetric horizontal tail: $\frac{\left.\delta_{m w}+\delta_{l w}\right), \text { degrees }}{2}$

$\delta_{r} \quad$ rudder deflection $\left(\frac{\delta_{r r}+\delta_{l r}}{2}\right)$, degrees

$l_{\text {ref }} \quad$ Hyper-X vehicle reference length 
$-$

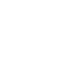

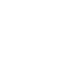

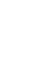

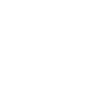

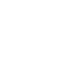

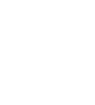

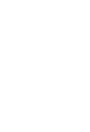

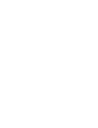

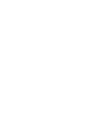

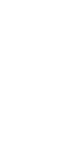

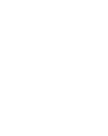

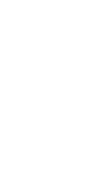

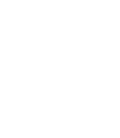

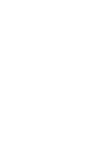

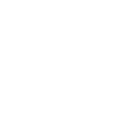




$$
\begin{aligned}
& q_{\infty} \quad \text { freestream dynamic pressure }\left(\frac{1}{2} \rho_{\infty} V_{\infty}^{2}\right) \\
& \mathrm{S}_{\text {ref }} \quad \text { Hyper-X vehicle reference area }
\end{aligned}
$$

\section{Introduction}

In 1996 NASA initiated the Hyper-X Program, a jointly conducted effort by the NASA Langley Research Center (LaRC) and the NASA Dryden Flight Research Center (DFRC), as part of an initiative to mature the technologies associated with hypersonic airbreathing propulsion. ${ }^{I}$ Unlike its predecessor, the U.S. National AeroSpace Plane (NASP) program, ${ }^{2}$ Hyper- $X$ is a very focused program which offers an incremental approach to developing and demonstrating scramjet technologies. During the NASP program, attempts were made to develop and integrate many new, unproven technologies into a full-scale flight test vehicle. In hindsight, this was an overly ambitious goal that was both technically and programmatically unachievable, given the relative immaturity of the various technologies and the budgetary constraints of the time. By contrast, the primary focus of the Hyper-X program is the development and demonstration of critical scramjet engine technologies, using several small, relatively low cost, flight demonstrator vehicles. This philosophy is a direct outcome of NASA's "better, faster, cheaper" approach to flight projects and programs in general.

The primary goals of the Hyper-X program are to demonstrate and validate the technologies, the experimental techniques, and the computational methods and tools required to design and develop hypersonic aircraft with airframe-integrated dual-mode scramjet propulsion systems. Hypersonic airbreathing propulsion systems, studied in the laboratory environment for over 40 years, have never been flight tested on a complete airframe integrated vehicle configuration. Three Hyper- $X$ flight test vehicles, the first two of which will fly at Mach 7, and the third at Mach 10, will provide the first opportunity to obtain data on airframe integrated scramjet propulsion systems at true flight conditions. ${ }^{3-5}$

The Hyper-X flight test program is first and foremost designed to test the operation and performance of an airframe integrated dual mode scramjet propulsion system. There are also a number of tier two goals of the program that are primarily aerodynamics related. The Hyper-X flight test program will provide a unique opportunity to obtain hypersonic aerodynamic data on a slender body, non-axisymmetric airframe. Because of the highly integrated nature of the propulsion system with the airframe, the traditional distinctions between vehicle aerodynam- ics and propulsion are blurred. So in addition to the scramjet operational and performance data that will be obtained, a tremendous amount of aerodynamics data will be gathered during the flight tests, both during and after the engine test, and will be telemetered back to ground stations in real time for post flight analysis. In addition to basic airframe aerodynamic stability and control information, each of the three Hyper-X Research Vehicle (HXRV) airframes are heavily instrumented with surface pressure, temperature and local strain gauge sensors.

\section{Hyper-X Flight Experiments - Vehicle Design and Mission Profile}

The HXRV design draws heavily on past vehicle configuration studies including the extensive NASP design database and several of the more recent U.S. hypersonic vehicle mission studies. ${ }^{6,7}$ Each of the three HXRVs, also referred to as the X-43A flight vehicles, are 12 feet long, weigh approximately $2700 \mathrm{lbs}$., and are scramjet powered, lifting body configurations, with all moving horizontal wings, and twin vertical tails with rudder surfaces (Fig. 1). The scramjet flowpath, which begins at the nose of the vehicles, utilizes the entire underside of the forebody as a compression surface. The scramjet engine combustor is located on the vehicle undersurface, slightly aft of midbody, and the aftbody undersurface comprises the external expansion surface for the scramjet exhaust flow. The initial conceptual design and internal subsystems definition for the X-43A configuration was performed by the former McDonnell Douglas Aerospace (now Boeing Co.) - St. Louis group. ${ }^{8}$ The scramjet engine flowpath definition and development activity was conducted primarily by researchers at NASA Langley Research Center. ${ }^{9}$ The vehicle preliminary design (referred to as the Government candidate design) was completed in October of 1996, and a team lead by Micro Craft, Inc. of Tullahoma, TN, was selected to fabricate and assemble the three $\mathrm{X}-43 \mathrm{~A}$ research vehicles.

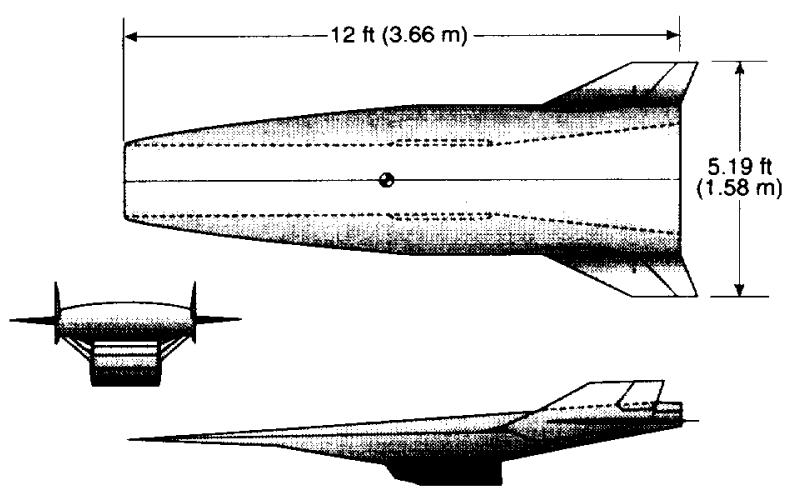

Figure 1. Hyper-X Research Vehicle / X-43A geometry. 
$-$ 
Each of the three X-43A vehicles will be individually boosted to the scramjet engine test points (Mach 7, Mach 7, and Mach 10 respectively) on modified versions of the first stage of the Orbital Sciences Corporation Pegasus Hybrid rocket. Orbital Sciences Corporation's Launch Services Group in Chandler, AZ is developing and building the three customized Pegasus launch vehicles for the Hyper-X flight experiments. The X-43A vehicle is attached to the first stage of the Pegasus booster by means of a specially designed conically shaped adapter that mates up under the aftbody expansion surface of the X-43A. This complete configuration, including the $X-43 \mathrm{~A}$ vehicle, the adapter, and the booster rocket is referred to as the Hyper-X Launch Vehicle (HXLV) or "stack" configuration and is shown in Fig. 2.

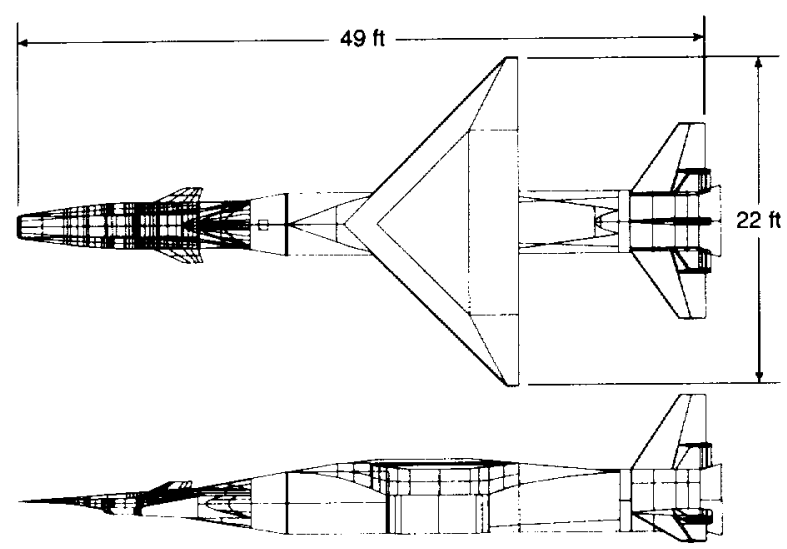

Figure 2. Hyper-XLaunch Vehicle (HXLV) configuration.
The HXLV stack is carried aloft under the wing of NASA's B-52 aircraft (Fig. 3), where it is dropped on a due west trajectory out over the Pacific Ocean at an altitude of approximately $19,000 \mathrm{ft}$. and a Mach number of 0.5 . Shortly after dispense from the B-52, the booster solid rocket motor is ignited and the HXLV flies an ascent profile to deliver the X-43A vehicle to the first flight test conditions of Mach 7 at an altitude of approximately $95,000 \mathrm{ft}$. as indicated in Fig. 4.

Once the HXLV reaches the scramjet engine test point condition, the X-43A vehicle is separated from the booster launch vehicle. This separation is accomplished by means of two ejection pistons that are driven by a set of manifolded high-pressure pyrotechnic gas generator charges. The

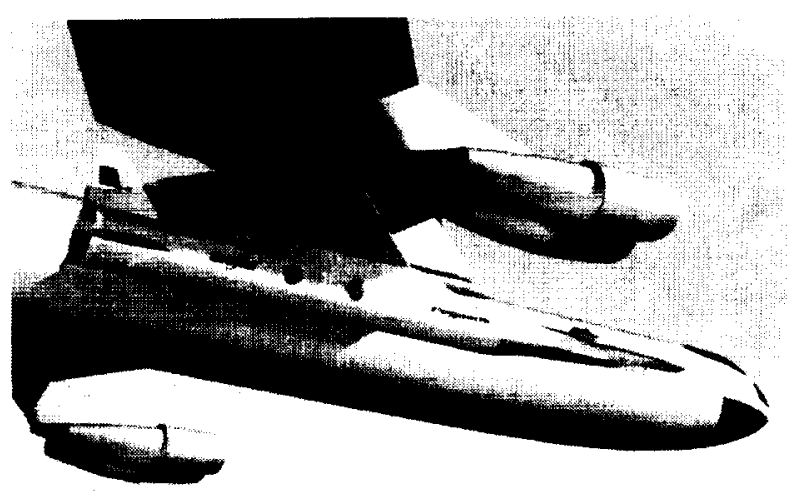

Figure 3. Artist's rendition of the HXLV being carried aloft on NASA's B-52 aircraft (from the Hyper-X flight profile video animation: http://lava.larc.nasa.gov/ MOVIES/MEDIUM/LV-1997-00005.mov).

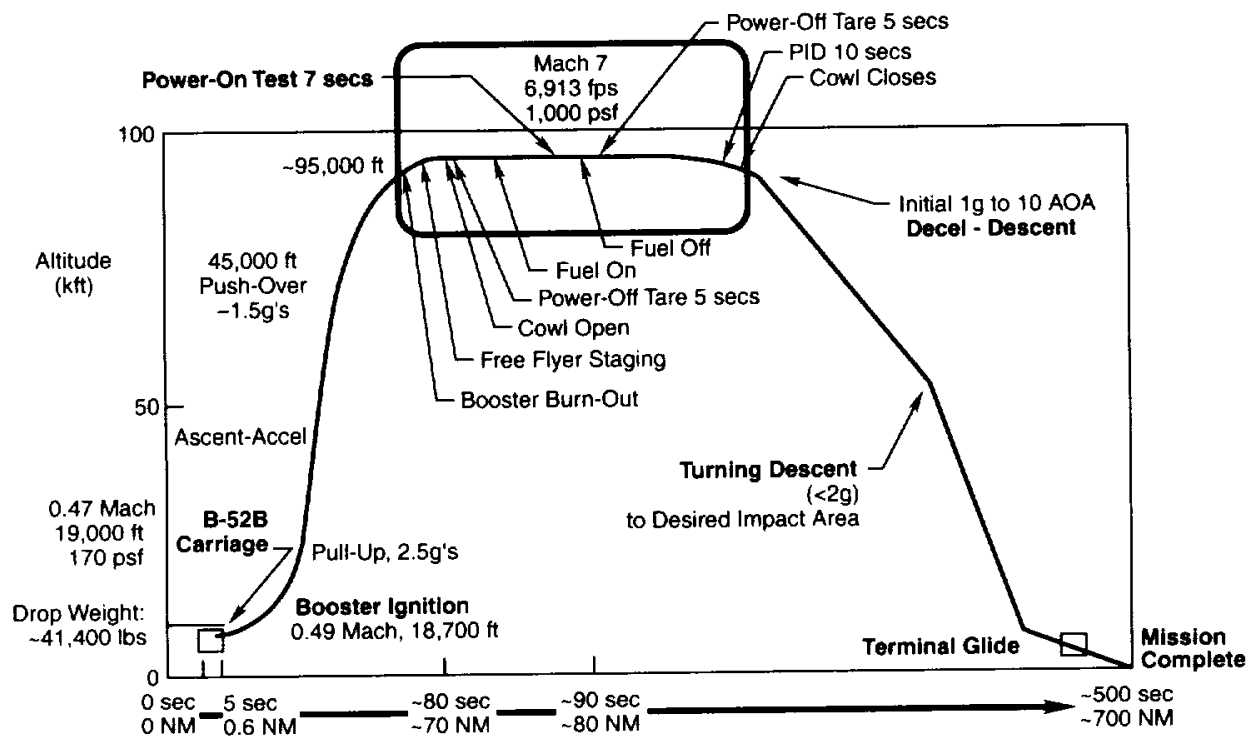

Figure 4. Nominal Mach 7 Hyper-X X-43A Flight Profile. 

pistons are mounted inside the front of the adapter and "push" on the base of the X-43A research vehicle in a direction which acts through the X-43A center of gravity (to avoid any large upsetting moments in the pitch plane). The entire stage separation sequence, which occurs over a period of less than 250 milliseconds, presents a number of extreme technical challenges. To the program's knowledge, there has never before been a successful demonstration of a controlled separation of two non-axisymmetric bodies at high the Mach numbers and dynamic pressure that will occur in the Hyper-X flight tests. Additional discussion of the details surrounding the development of the current stage separation scenario and several of the hardware ground tests can be found in Ref. 10 .

Immediately following the stage separation event, the X-43A control system stabilizes the vehicle and the scramjet test portion of the experiment will begin. The scramjet engine inlet door (which protects the internal engine components from the high heat loads during ascent to the test condition) will be opened, and the scramjet fueling sequence will commence. A combination of $\mathrm{Si}$ lane $\left(\mathrm{SiH}_{4}\right)$ and gaseous hydrogen $\left(\mathrm{H}_{2}\right)$ is injected into the combustor region, resulting in powered scramjet engine operation. Silane is used only during the initial ignition process, after which pure hydrogen is injected and combusted. After the fuel is depleted, the flight vehicle will record several seconds of engine-off aerodynamic tare data, then the inlet cowl door will be shut and the vehicle will fly a controlled deceleration trajectory as it descends and decelerates through the supersonic and transonic flight regimes prior to flight termination at subsonic conditions.

The first of three Hyper-X X-43A flight vehicles was delivered to NASA DFRC in October of 1999 and is shown in Fig. 5. This vehicle is currently undergoing hardware and aircraft in the loop testing and systems

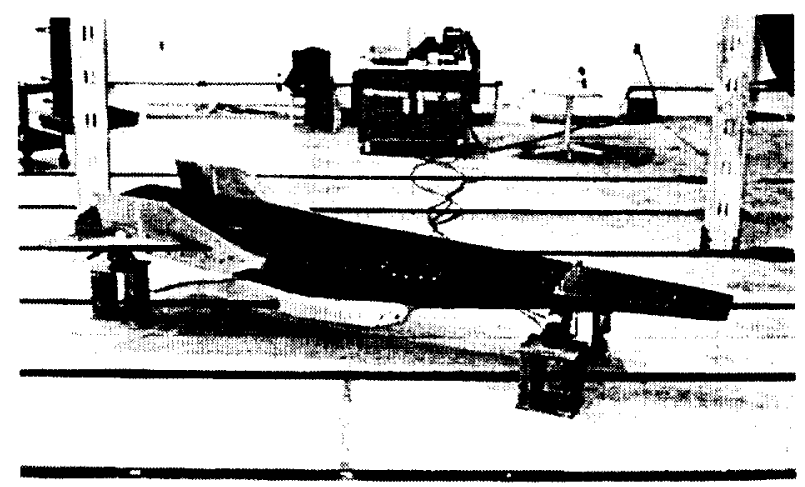

Figure 5. The Hyper-X X-43A Airframe No. I at NASA's Dryden Flight Research Center.

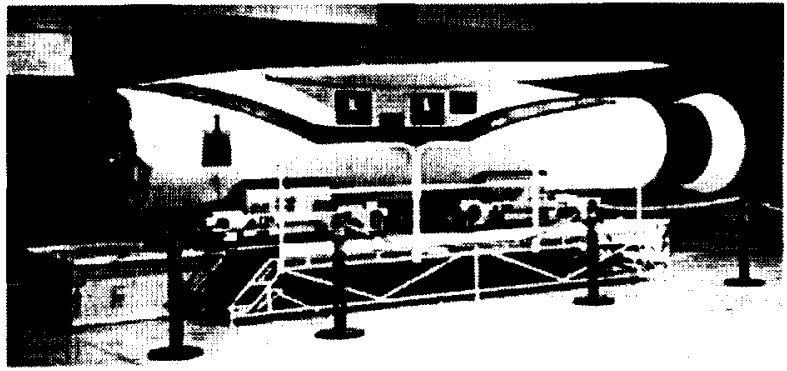

Figure 6. The Hyper-X Launch Vehicle prior to mating
at NASA's Dryden Flight Research Center.

checkout. Once the systems tests are complete on the first $\mathrm{X}-43 \mathrm{~A}$ vehicle, it will be mated to the HXLV rocket booster configuration, shown in Fig. 6, via the RV/LV adapter, in preparation for the first flight test, scheduled to take place in the fall of 2000. The subsequent second and third flight tests are planned occur at approximately one year intervals after the first flight.

\section{Hyper-X Flight Experiment Aerodynamic Ground Test and Analysis Efforts}

Immediately following program authorization in 1996, an extensive ground test program commenced for the preflight aerodynamic and propulsion database development, verification, validation and risk reduction activities. Aside from the specific propulsion aspects of the program, the development of the aerodynamic models and database to support the Hyper-X flight experiments have provided a number of unique aerodynamics challenges, which have been addressed though comprehensive wind tunnel testing, computational fluid dynamics (CFD) and analytical methods analysis. The Hyper$\mathrm{X}$ aerodynamic database is comprised of data which supports the mission through all phases of flight, beginning with the HXLV dispense from the B-52, the ascent of the HXLV to the test conditions, the separation of the $\mathrm{X}-43 \mathrm{~A}$ vehicle from the HXLV, the engine test including the powered and unpowered post test tare measurements, and the descent of the research vehicle to subsonic terminal conditions. A brief description of the preflight ground based aerodynamic wind tunnel testing and computational analysis activities follows, with additional references provided to more specific detailed documents where available. Additional details regarding the Hyper$\mathrm{X}$ propulsion system ground test and analysis program may be found in Refs. 9, 11, and 12 .

\section{Hyper-X Launch Vehicle}

The Orbital Sciences Corporation is responsible for the development of the Hyper-X Launch Vehicle config- 

uration which will deliver each of the Hyper-X X-43A vehicles to their respective test conditions at Mach 7 and 10. During the initial portion of the ascent following the dispense from the B-52 and subsequent solid rocket motor ignition, the HXLV flies a typical Pegasus launch vehicle profile, ${ }^{13}$ which includes a high angle-of-attack lifting pull up maneuver through the transonic regime, followed by a pushover to low angle-of-attack flight at approximately Mach 2 and beyond. Unlike the standard Pegasus launch vehicle, which quickly exits the sensible atmosphere, the HXLVs fly a high Mach number depressed trajectory profile in order to deliver the X-43A vehicles to the Mach 7 and 10 test conditions at a dynamic pressure of approximately $1000 \mathrm{psf}$. In order to define basic airframe aerodynamic characteristics over the entire ascent Mach envelope, wind tunnel testing of the HXLV configuration was conducted by Orbital in a number of different wind tunnel test facilities, including several entries in the Lockheed-Martin Vought High Speed tunnel in Ft. Worth TX, and entries in NASA Langley's $16-\mathrm{ft}$ Transonic facility, 20 -in Mach 6, and 31-in Mach 10 tunnels. A photograph of the $3 \%$ scale model of the HXLV being tested in the LaRC 20-in Mach 6 facility is shown in Fig. 7. An extensive amount of CFD analysis was conducted on the HXLV configuration, primarily to define pressure and thermal load distributions over the entire ascent trajectory, as well as to cross check basic force and moment results obtained in the wind tunnel test activities. Reference 14 provides specific details regarding the HXLV aerodynamic design and developmental efforts.

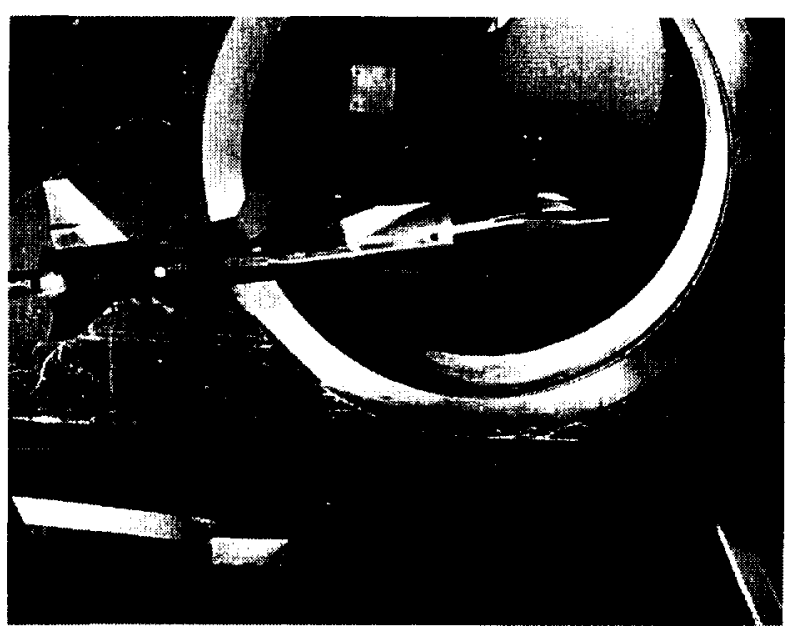

Figure 7. The Hyper-X Launch Vehicle configuration undergoing wind tunnel testing in the NASA Langley 20-in Mach 6 facility.

\section{Stage Separation}

The X-43A stage separation from the HXLV, which will occur at the extreme environmental conditions associated with flights at Mach 7 and 10, and dynamic pressures of approximately $1000 \mathrm{psf}$, is a complicated dynamic event which must be executed precisely so as not to upset the $\mathrm{X}-43 \mathrm{~A}$ in a manner such that it cannot obtain the steady, controlled flight conditions required to conduct the scramjet engine test. A series of wind tunnel tests were conducted in order to assess the aerodynamic forces and moments associated with this two body, mutual interference separation problem. Preliminary estimates of the aerodynamic interference effects were obtained by modifying a wind tunnel model of an early X-43A configuration to permit a non-metric HXLV conical adapter to be clamshell mounted directly on the model sting. Several screening tests conducted in the NASA Langley 20 -inch Mach 6 and 31 -inch Mach 10 wind tunnels provided a rapid initial assessment, but permitted only axial separation between the X-43A model and adapter (no relative vertical or lateral translation and no relative angular displacement), and measured only the effect of the adapter on the research vehicle aerodynamics (as opposed to the simultaneous mutual interference of the two bodies on each other). Once the proof of concept had been defined, a high fidelity, $8.33 \%$ scale, multi-component model, which included the entire HXLV configuration, was built and tested at the Arnold Engineering Development Center - vonKarman Gas Dynamics Facility (AEDC-VKF) Tunnel B, at Mach 6 test conditions. Six component force and moment data were obtained for both the X-43A and the HXLV booster+adapter combination in close proximity to each other. A photograph of the stage separation model hardware in the AEDC VKF Tunnel B facility is shown in Fig. 8.

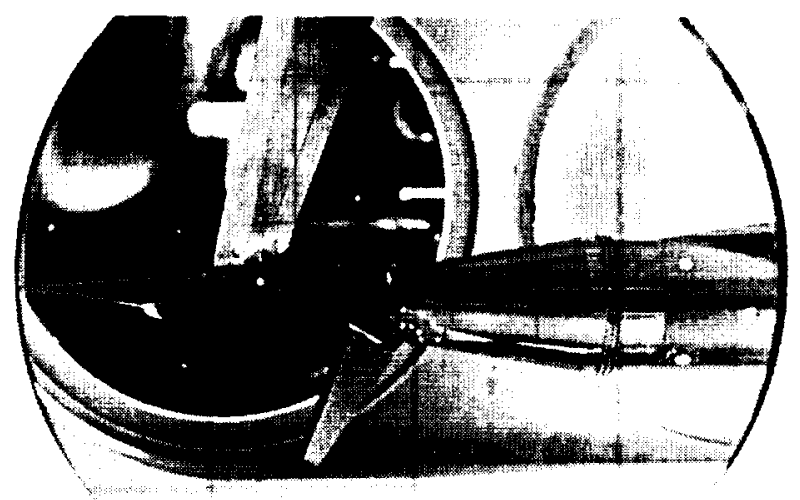

Figure 8. Hyper-X Stage Separation Test Hardware in the AEDC VKF Tunnel B facility. 
- 
The AEDC test utilized a captive trajectory system (CTS) rig that allowed the HXLV booster+adapter model to be translated and rotated relative to the fixed X-43A model in order to obtain test data over a broad matrix of relative orientations between the $\mathrm{X}-43 \mathrm{~A}$ and the $\mathrm{HXLV}$ booster+adapter bodies. Additional test entries were conducted in the NASA Langley 20-inch Mach 6 and 31 inch Mach 10 facilities using the same $8.33 \%$ model of the X-43A and the HXLV adapter block alone in order to assess the Mach number dependency of the stage separation problem. These two facilities are much smaller than that of the AEDC VKF Tunnel B, and cannot accommodate the entire X-43A and HXLV booster+adapter configuration. In addition, they are both blowdown tunnels and their associated productivity is much lower than that of the continuous flow AEDCVKF. They are much less expensive to test in however, and were utilized for screening tests to determine the Mach number dependency of the problem. Additional details of the Hyper-X stage separation wind tunnel test program can be found in Ref. 15 .

CFD analysis has also played an important role in the Hyper-X stage separation design and database development efforts. All of the wind tunnel experiments conducted in support of the stage separation aerodynamic characterization have been steady state tests. Issues associated with unsteady flow, in particular the establishment of the flowfield within the cavity between the $X$ 43A aftbody and the adapter forebody as the two bodies move apart, have been addressed using state-of-the-art CFD analysis methods (including both structured and unstructured grid flow solvers). Several steady state CFD solutions, including full viscous (Navier-Stokes) and inviscid (Euler) analyses, were analyzed at the wind tunnel test conditions and scale. These same cases were also run at steady state flight conditions and scale to determine tunnel to flight scaling relations. The unsteady nature of the flow establishment within the cavity formed by the X-43A nozzle aftbody and the adapter forebody during the separation has been addressed using fully time accurate CFD solutions (both viscous and inviscid analyses). Additional CFD analyses were conducted to provide insight into separation conditions (relative orientations between the two bodies) that were not captured in the AEDC test matrix. Data from the exhaustive CFD analysis efforts, which are described in further detail in Ref. 16, along with the experimentally derived wind tunnel data, have been integrated together and are being used as input to a multibody 15 degree-of-freedom stage separation simulation tool developed specifically for the analysis of the Hyper-X stage separation event. This tool has proven to be invaluable in the evaluation and development of the sequencing and event timing (e.g. optimal vehicle attitude, control surface position and rates, piston motion, etc.) in order to enable successful stage separation at the high Mach number and dynamic pressure conditions.

\section{$\underline{X-43 A}$ Vehicle}

"An early lesson of high speed flight was that proper aerodynamic integration of the ramjet of scramjet with the remainder of the vehicle is critical to success... ." 17 In order to fully address all of the issues associated with the highly integrated nature of the scramjet engine with the X-43A airframe, an extensive combination of wind tunnel testing and $\mathrm{CFD}$ analysis has been required to determine the vehicle's aerodynamic and propulsion characteristics. This is particularly true during the scramjet powered portion of flight where the aftbody of the airframe serves as the nozzle expansion surface for the high energy exhaust from the engine. This can, and in fact does, have a significant impact on the vehicle's overall aerodynamic characteristics and will be briefly described in the following discussion.

In order to develop the parametric aerodynamic and propulsion analysis force and moment database which fully encompassed the anticipated flight conditions at and around the engine test point (including variations in Mach number, angle-of-attack, angle-of-sideslip, engine fuel equivalence ratio, etc.), an airframe force accounting strategy was developed such that forces and moments associated with aerodynamic and propulsion flowpath surfaces could be properly bookkept by the aerodynamics and propulsion groups. This basic force accounting strategy for the X-43A vehicle is indicated by Fig. 9.

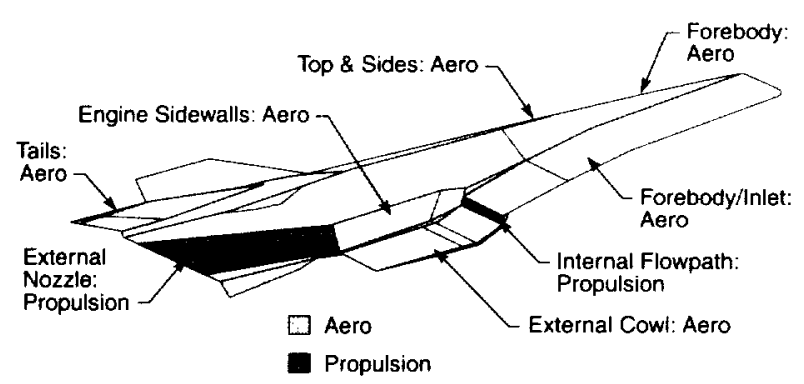
Figure 9. X-43A Force accounting methodology for
flight during inlet open conditions.

Early in the program, initial wind tunnel screening tests were conducted to determine the basic X-43A airframe aerodynamics, including stability, control, and performance characteristics. These "quick look" tests were conducted using small scale, rapid fabrication models in the Langley 20-inch Mach 6 and 31 -inch Mach 10 facil- 
ities, the Boeing (formerly McDonnell Douglas) - St. Louis Polysonic tunnel, and the Boeing North American subsonic tunnel. As the vehicle design matured, additional testing was conducted using larger, higher fidelity models, with very fine gradations in control surface increments. Additional entries using the refined high fidelity models were made in the NASA Langley $16-\mathrm{ft}$ Transonic facility $(0.6<$ Mach $<1.2)$, Unitary Plan Wind Tunnel facility $(1.5<$ Mach $<4.6)$, the 20 -inch Mach 6 , and the 31 -inch Mach 10 tunnels, in order to fully bracket the anticipated flight envelope. A photograph of one of the $X-43 A$ models in the Langley Unitary Plan Wind Tunnel is shown in Fig. 11. Further details of the complete ground based wind tunnel test program conducted in support of the Hyper-X flight experiment are provided in Ref. 18.

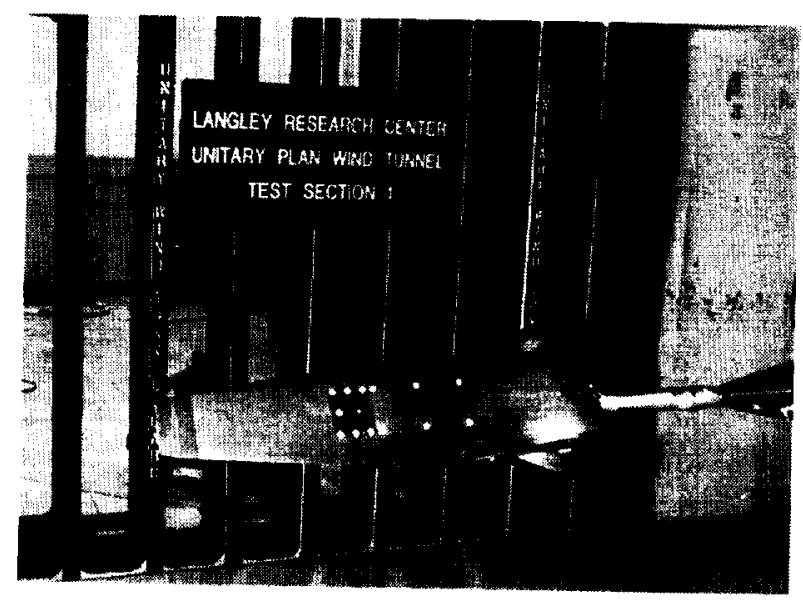

Figure 10. The Hyper-XX-43A configuration in the NASA Langley Unitary Plan Wind Tunnel.

Due to the relatively small scale of these aerodynamic force and moment wind tunnel models, inlet-open testing (unpowered or powered using a simulant gas technique ${ }^{19}$ ) was not possible. A comprehensive CFD study ${ }^{20}$ was undertaken to provide estimates of the inlet-open unpowered and powered flight aerodynamic characteristics for the Mach 7 vehicles, including the effects of Mach number, angle-of-attack, and sideslip on the X43A. A number of different CFD codes and tools were utilized to predict the airframe forces and moments associated with the inlet open flight conditions, including both unpowered and powered engine operation modes. These methods included CFD codes, both structured Euler and Navier-Stokes solvers, for external airframe analysis, and propulsion cycle analysis codes which model the scramjet combustion physics and flowpath processes. The strategy employed within the Hyper-X program has been to utilize the inlet closed wind tunnel data as an anchor, and to develop a set of airframe force and moment increments using CFD and analytical tools to model inlet open characteristics. The first step in this process was to validate and benchmark the CFD codes and methods against the inlet closed wind tunnel data. An example of this validation effort is shown in Fig. 11. Basic longitudinal aerodynamic characteristics (lift, drag, and pitching moment), experimentally obtained in the NASA LaRC 20-inch Mach 6 wind tunnel are shown as functions of angle-of-attack and elevator (symmetric tail) deflection angles. These data indicate well behaved, relatively linear lift characteristics over the anticipated flight angle-of-attack and elevator deflection angle range. The pitching moment coefficient data, shown here as a function of angle-of-attack for elevator deflection angles of $0,7.5$ and 15 degrees, indicate an airframe with positive longitudinal stability (negative $\mathrm{Cm}$ slope) up to anglesof-attack of approximately eight degrees. An elevator deflection angle of approximately seven degrees is required to trim the vehicle at the nominal Mach 6, two degree angle-of-attack flight condition for the inlet closed configuration data shown here. Results from a series of inviscid CFD solutions obtained at Mach 6 conditions at each of zero, two, and four degrees angle-of attack, all with zero degree elevator deflection, are also included on the plots of figure 11. The CFD predicted results for the lift and pitching moment values agree relatively well with the wind tunnel data, while the discrepancies in the CFD drag predictions are due primarily to the fact that they were obtained from an inviscid analysis; the higher drag coefficient data obtained in the wind tunnel are directly attributable to the viscous (skin friction) effects. These results helped build confidence in the CFD tools and methodologies, and the ability to accurately predict the airframe forces and moments at and around the test condition.

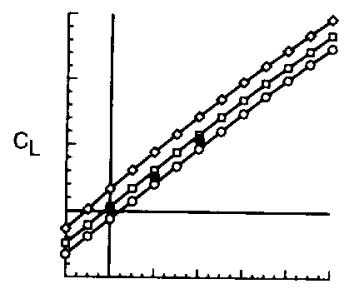

$$
\begin{aligned}
\multimap-\delta_{\text {elv }} & =0^{\circ}, \exp \\
\rightarrow-\delta_{\text {elv }} & =7.5^{\circ}, \exp \\
\multimap-\delta_{\text {elv }} & =15^{\circ}, \exp \\
-\delta_{\text {elv }} & =0^{\circ}, \text { CFD (GASP, Euler) }
\end{aligned}
$$
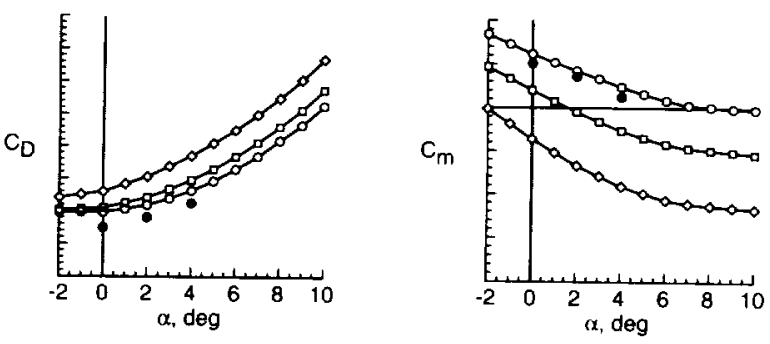

Figure 11. X-43A Mach 6 basic longitudinal aerodynamic characteristics (Wind Tunnel and CFD results). 
$-$

$\longrightarrow$

$-\longrightarrow$

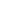


The basic inlet open, unpowered and powered, CFD predictions have been verified experimentally at several discrete flight test conditions (including multiple anglesof-attack) by a full scale propulsion flowpath test conducted in the NASA Langley 8 - $\mathrm{ft}$ High Temperature Tunnel (8-ft HTT). ${ }^{12}$ A model referred to as the Hyper$X$ Vehicle Flowpath Simulator (VFS), which duplicates the X-43A lower surface flowpath and chine surfaces, along with an identical scramjet engine (flight spare) referred to as the Hyper-X Flight Engine (HXFE), were tested in the 8-ft HTT (Fig. 12).

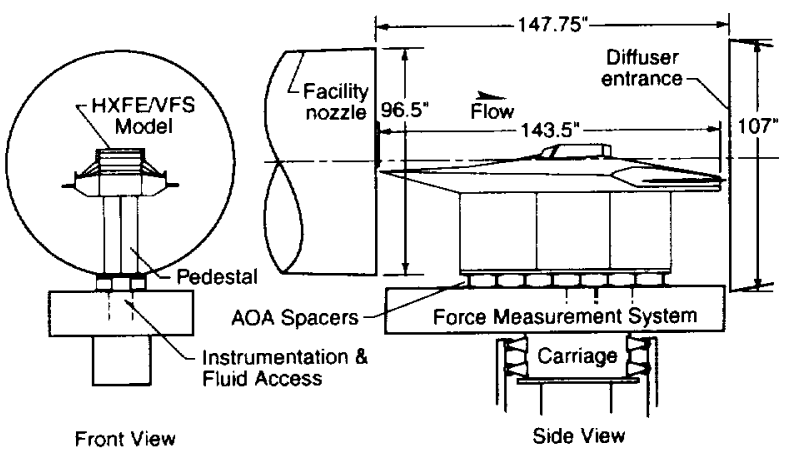

Figure 12. Diagram of the Hyper-X Vehicle Flowpath Simulator and Hyper-X Flight Engine installation in the NASA Langley 8 ft HTT.

The 8-ft HTT facility provides the unique capability to test the full scale VFS/HXFE model at representative flight conditions (Mach number, pressure, and enthalpy). The primary intent of this test was to verify the propulsion system fuel sequencing and operation, and to provide a preflight, ground based experimental validation of the CFD predictions of surface pressures, and the aerodynamic force and moment increments that result from the cowl inlet opening and closing and the fueled (powered) portion of the flight. Because the VFS/HXFE is not an accurate representation of the entire X-43A geometry, the total forces and moments measured during the test are not relevant; however, all of the VFS/HXFE flowpath surfaces including the forebody, internal engine components, and aftbody nozzle expansion surfaces are identical to those of the $\mathrm{X}-43 \mathrm{~A}$ vehicles, so that the force and moment increments associated with opening the inlet cowl door and the subsequent engine operation are accurately modeled by this test. The lift, drag, and pitching moment increment results from this test at the Mach 7 conditions and the comparison with the CFD predictions are shown in Fig. 13. Basic lift, drag, and pitching moment data are shown for the zero degree elevator deflection, inlet door closed configuration. These data were derived from the Mach 6 wind tunnel test data and a set of CFD derived increments, which account for the Mach
6 to Mach 7 condition scaling. CFD analysis was also utilized to develop the force and moment increments associated with opening the inlet door and with the scramjet powered engine operation. Inspection of the basic pitching moment data indicates that a slight nose down moment increment is expected as a result of opening the inlet door. The inlet door, in the closed position, can be viewed as a third forebody compression ramp. The high pressure acting over this surface, which is located well below and slightly aft of the vehicle c.g., acts to pitch the vehicle down. By opening the door, the compression angle is effectively reduced, as is the ramp orientation relative to the c.g., which results in a nose up pitching moment associated with this surface motion. However, by opening the inlet door, flow through conditions are established and the aftbody nozzle expansion surface is pressurized, which tends to pitch the vehicle down. These two opposing effects tend to cancel each other, and the net result is a very slight nose down pitch increment. The increment requires approximately five degrees of elevator deflection to trim at the nominal two degree angleof-attack test condition (vs. the approximately 6 degree deflection required for inlet closed operation at Mach 7). At the same time, the act of opening the inlet door results in a substantial loss of lift and drag on the vehicle. This is due primarily to the loss of the contribution to lift and drag of the pressure forces acting normal to the inlet door in its closed position.
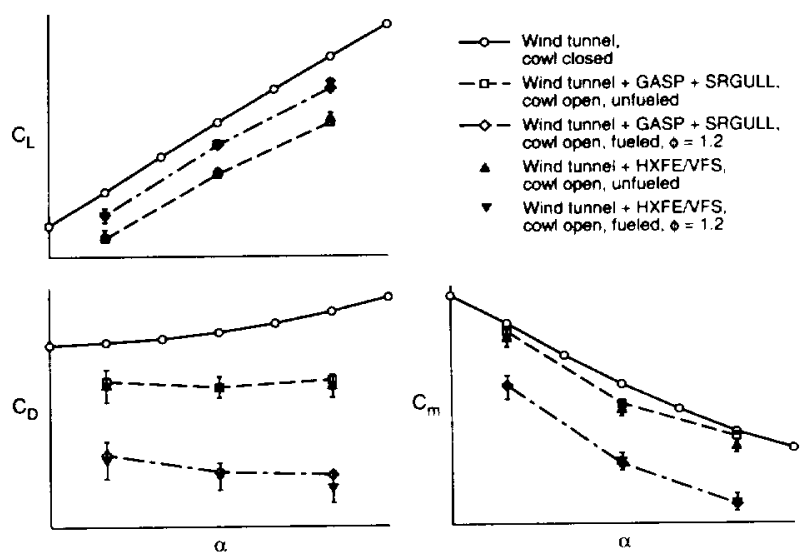

Figure 13. X-43A longitudinal forces and momentsinlet open unpowered and powered modes (including validation results from the $8-f t H T T$ ).

In the nominal scramjet powered operation mode (inlet open, power-on data of Fig. 13), there is a substantial nose down pitching moment. In this case, two opposing sets of forces act to produce a net nose down moment increment. The momentum flux exiting the scramjet engine combustor (located below the vehicle c.g.) produces a slight nose up moment; this, however, is small in 

comparison to the nose down moment increment that is a result of the aftbody nozzle surface area of the vehicle being pressurized by the high energy expanding scramjet exhaust flow. In addition to the net nose down moment increment, nominal scramjet operation provides a substantial increment in overall lift, as a result of the highly pressurized scramjet exhaust flow acting over the nozzle aftbody. Because of the large nose down moment increment, the required elevator deflection angle to trim the configuration at two degrees angle-of-attack is effectively reduced to zero. This is advantageous from a vehicle performance point of view because of the fact that large trim drag penalties are associated with the elevator surface deflections. During nominal scramjet engine operation the trim drag penalty is effectively zero, which should maximize the vehicle performance margin. This issue of aerodynamic trim drag is a key design consideration which must be taken into account for future hypersonic vehicles that will utilize airframe integrated propulsion systems.

It is also worth noting the agreement between the inlet-closed wind tunnel + CFD derived increments and the results from the $8 \mathrm{ft}$ HTT test. In general, excellent agreement was obtained between these two independent methods, adding further confidence in the ability to accurately predict the combined aero-propulsive force and moment characteristics of the airframe during engine operation.

Significant efforts have also been made in order to address airframe lateral-directional characteristics during scramjet engine operation. Once again, because all of the X-43A vehicle force and moment wind tunnel tests were conducted using the relatively small scale models with closed inlets, questions arose regarding the effects of inlet open operation, both during powered and unpowered modes, on the lateral-directional stability and control characteristics. At issue was the question of the effect of vehicle sideslip and the expanding propulsion plume acting over the vehicle aftbody, and whether or not the plume would tend to increase or decrease the configuration's basic lateral-directional stability characteristics. An additional series of CFD solutions were generated to address this issue. The results, reported in Ref. 20 , indicate that in the case of the $\mathrm{X}-43 \mathrm{~A}$ configuration there is no significant direct effect of inlet open, powered or unpowered engine operation, on the basic airframe lateral-directional stability.

Examination of figure 14 indicates however, that there is an indirect effect of the inlet open unpowered/ powered operation on the airframe's lateral-directional characteristics. Recall that for the nominal Mach 7, 2

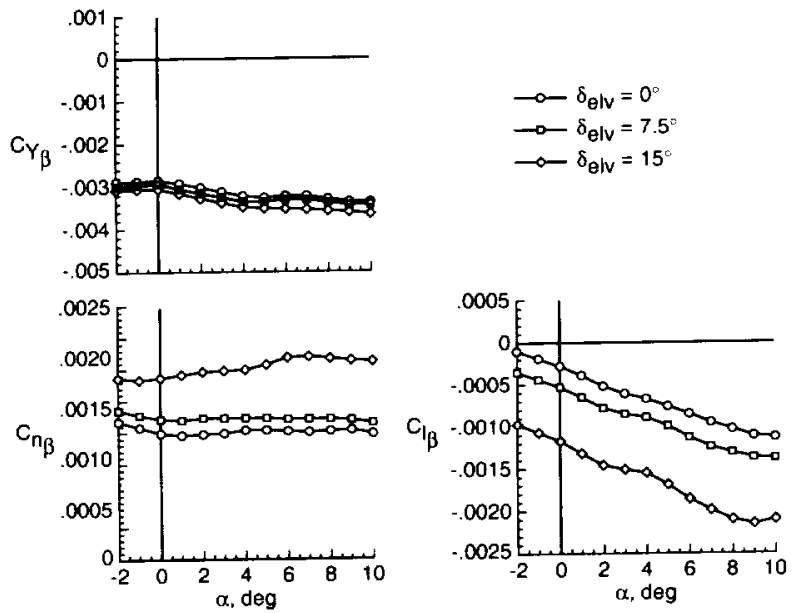
Figure 14. Effects of elevon position on the HXRV
basic lateral-directional characteristics.

degree angle-of-attack flight condition, approximately 6 degrees of elevator deflection is required to trim the vehicle in the inlet closed configuration, while the inlet open, powered configuration trims with a near zero elevator position. The data presented in Fig. 14 indicate the fact that there is a strong dependence of both $C_{1_{\beta}}$ and $C_{n_{\beta}}$ on the nominal elevator position. At the nominal 2 degree angle-of-attack condition, there is a near $60 \%$ increase in the magnitude of the $C_{B_{\beta}}$ term for elevator deflections of 7.5 degrees vs. 0 degrees, and a $17 \%$ increase in the $C_{n_{\beta}}$ characteristic. Sideslip induced side force $\left(C_{Y_{\beta}}\right)$ remains moderately unaffected by elevator position.

Additional control surface interaction effects were also explored. The effect of elevator position on the aileron control power at Mach 7 flight conditions is shown
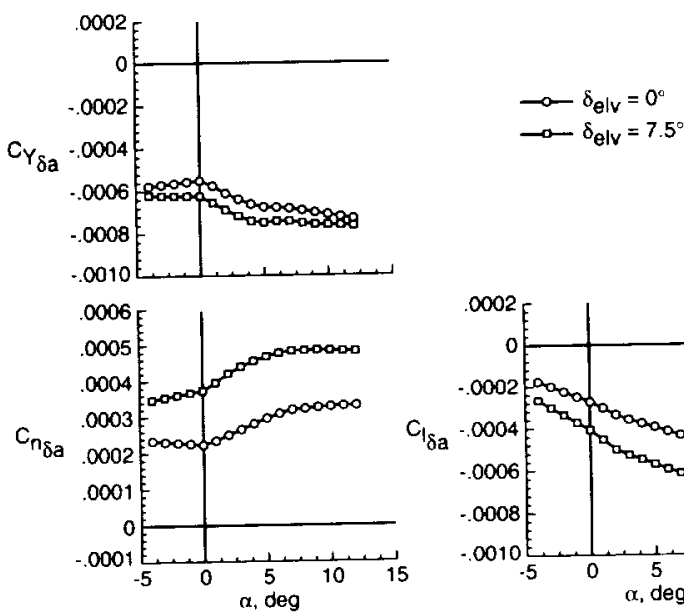

Figure 15. Effect of elevator position on the HXRV aileron control effectiveness. 
- 
in Figure 15. The side force, and yaw and roll moment coefficients due to linearized aileron deflections (per degree) are plotted against vehicle angle-of-attack. For the Hyper-X vehicle, aileron deflections are defined by asymmetric tail deflection about a nominal elevator (tail) position. For example, $a+5$ degree aileron deflection about a 0 degree elevator deflection would require a 2.5 degree left tail deflection and a +2.5 degree right tail deflection. The figures indicate a strong dependence of aileron effectiveness on the nominal elevator deflection angle. In particular, the aileron roll effectiveness is almost $70 \%$ greater about a 7.5 degree elevator deflection as opposed to a 0 degree elevator deflection.

The fact that $\mathrm{C}_{\mathrm{I}_{\mathrm{\beta}}}$ and $\mathrm{C}_{\mathrm{n}_{\beta}}$ and the aileron control power all have a strong dependency on elevator position, and elevator position is a direct function of inlet door position and engine power, indicates an indirect effect of engine operation on the basic airframe lateral-directional behavior and control power characteristics. This fact must be accounted for in the control law design and analysis efforts for this, and any other similar hypersonic vehicles with highly integrated propulsion systems.

The rudder effectiveness data at Mach 7 flight conditions, including the effects of elevator position, are shown in Fig 16. At low angles-of-attack, the rudders have a moderate amount of effectiveness, which appears to be only minimally affected by the elevator position. However, as angle-of-attack increases, the rudders tend to lose effectiveness in a rather dramatic fashion. In fact, at angles-of-attack approaching 10 degrees, the rudders are almost completely ineffective. This is due primarily to the crossflow separation occurring over the vehicle forebody which tends to bury the vertical tails and rud-
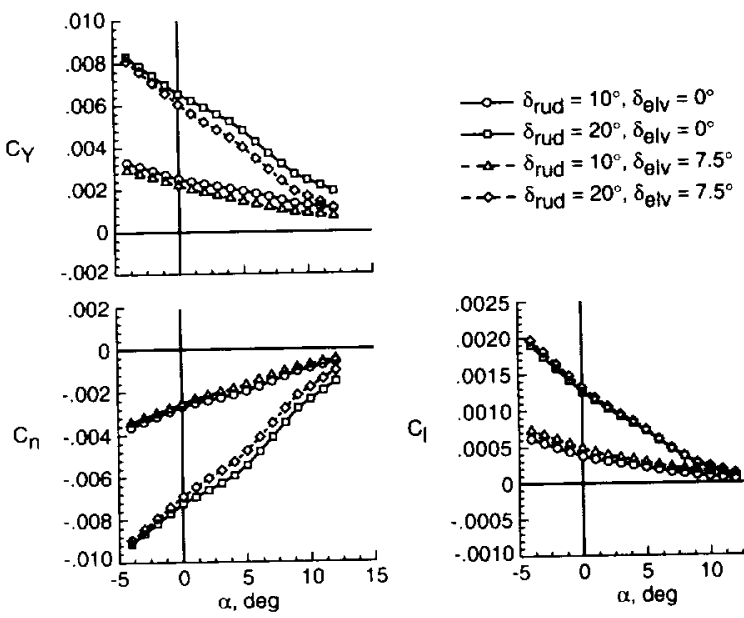

Figure 16. Effect of elevon position on the HXRV basic rudder control effectiveness. ders in a low energy wake flow (the so-called "hypersonic shielding effect"). The X-43A design test point is at an angle-of-attack of two degrees, a condition at which the rudders do provide some degree of directional control authority. However, at a point in the flight trajectory beyond the engine test and post test tares, the vehicle must pull up to an angle-of-attack of approximately 10 degrees in order to generate enough lift to maintain altitude. At this condition, the rudders will provide little in the way of directional control, and the vehicle will be forced to rely on alternate methods for directional control authority and stability augmentation.

Beyond the extensive efforts to quantify the X-43A vehicle's aerodynamic performance, stability, and control parameters, additional testing and analyses have been conducted to address other aerodynamic related issues as well. In order to minimize shock induced flow separation internal to the scramjet engine, it is desirable to ensure that the boundary layer ingested into engine inlet is fully turbulent. Estimations of the onset of transition (based on a limited amount of flight hypersonic boundary layer transition data) at the X-43A engine test conditions suggested that forebody boundary layer trip devices would be required to ensure fully turbulent conditions at the scramjet engine inlet. Significant efforts have been made to quantify a forebody flowpath boundary layer trip design that will be utilized on the X-43A vehicles. A $33 \%$ scale X-43A forebody model was utilized to conduct a wind tunnel investigation of boundary layer trip effectiveness and the impact on the airflow entering the engine and along with the associated forebody aerothermal loads. Initial trip designs were developed utilizing CFD analysis methods and wind tunnel tests were conducted to confirm the results and refine the boundary layer trip design. Further details of the boundary layer trip design study are provided in Ref. 21 .

Finally, a series of tests were conducted in the AEDC VKF Tunnels $A$ and $B$ in order to fully characterize the $\mathrm{X}-43 \mathrm{~A}$ forebody pressure distribution with respect to Mach number, angle-of-attack and sideslip. The forebody of the X-43A flight vehicles are instrumented with a series of nine pressure transducers (one located at the nose apex, two on the upper surface centerline, two on the lower surface centerline, and two each on the starboard and port forebody chines). These surface pressure measurements, referred to as the Flush Air Data Sensor (FADS) systern, will be utilized to derive in-flight air data parameters (Mach number, dynamic pressure, static pressure, angle-of-attack, angle-of-sideslip, etc.). Preliminary FADS forebody pressure models were derived using a series of analytic and CFD derived pressure distributions. Wind tunnel tests were then conducted in the AEDC fa- 

cilities over a range of Mach numbers $(2.0-8.0)$ using an $80 \%$ of full scale forebody model instrumented with the full array of nine pressure transducers. The results of these tests are currently being used to mature the set of forebody pressure models from which the in-flight air data parameters can be determined as a function of the forebody pressure distributions. Additional details on the FADS concept and the implementation on the X-43A flight test vehicle may be found in reference 22 .

\section{Flight Data Analysis and Trajectory Reconstruction}

During each of the three X-43A flight test sequences, a series of preprogrammed aerodynamic maneuvers will be conducted in order to assess the basic aerodynamic stability and control characteristics of the vehicles at true operating flight conditions. Stability and control derivatives will be estimated by examining vehicle dynamic response to a series of preprogrammed elevator, aileron, and rudder doublets which will occur at various points in the flight trajectory. For the first Mach 7 flight, these maneuvers will be limited to the unpowered portion of flight; however, the second Mach 7 flight test profile may incorporate several maneuvers into the scramjet powered portion of the experiment, thus providing data on the propulsion system and airframe aerodynamic coupling effects under dynamic conditions.

Because the engine test duration of the first flight is limited to less than 10 seconds, extensive stability information will not be obtained for the powered configuration. However, immediately prior to and following the engine test, several seconds of tare data will be taken with the inlet door in the open position. Because of the high heat loads in the combustor region flowpath, the inlet door must be returned to the closed position shortly after the engine test is complete, and remain closed for the duration of the descent. Therefore, the majority of the flight extracted stability and control information will be obtained on the inlet closed configuration. Sequential Single Surface Inputs $\left(\mathrm{S}^{3} \mathrm{I}\right)$ for each of the elevator (pitch), rudder (yaw) and aileron (roll) surfaces will be employed, with 3-2-1-1 doublet step input profiles applied in order that time constant information can be extracted from the measured response. ${ }^{23.24}$ These preprogrammed inputs will occur at specific intervals during most of the descent trajectory in order to capture the airframe's three axis stability and control characteristics over as much of the flight Mach envelope as possible. The inlet closed X-43A airframe drag characteristics will be captured by conducting a series of Push-Over/Pull-Up (PO/PU) angle-of-attack traversals. These maneuvers, which will also occur at specific intervals during the descent trajectory, will allow for drag polar (CD vs. CL or CD vs. $\alpha$ ) estimation at various flight Mach numbers. Simulated trajectory data for the first Mach 7 flight are shown in Fig. 17, with Mach number, angle-of-attack, and elevator deflection angles plotted as a function of time. The high and low frequency control surface pulses and associated vehicle angleof-attack response can clearly been seen over the entire planned decent trajectory.
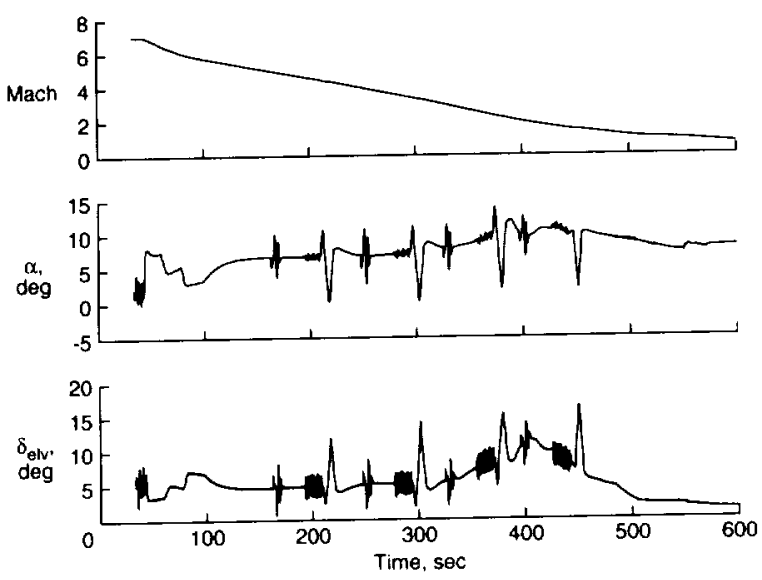

Figure 17. Post test descent trajectory angle-of-attack and control surface deflection profiles with PID and PO-PU maneuvers.

In addition to the basic airframe aerodynamic stability and control parameter estimation efforts, the X-43A will be extensively instrumented with close to 200 individual pressure transducers and thermocouples. Because the first priority of the Hyper-X program is to obtain data on the operating scramjet engine, a large percentage of the instrumentation is located within the combustor. There are, however, a significant number of pressure and temperature measurements that will be taken on the external surfaces, including the propulsion flowpath (forebody ramps and inlet, and the aftbody nozzle expansion surface) and the external airframe (forebody chines, lee/ topside, and the vehicle base). The location and layout of the external pressure transducers and thermocouples are shown in figure 18. An enormous amount of data will collected during each flight. The nominal pressure transducer sample rate is $50 \mathrm{~Hz}$, and the thermocouples sample at $20 \mathrm{~Hz}$. For each of the three approximately 15 minute flights, the data will be taken and telemetered back to ground stations for storage and post flight analysis. The data obtained from these measurements will allow for direct comparison with the preflight CFD and analytic solutions that have been developed in support of the overall aerodynamic database effort. 
$=$ 

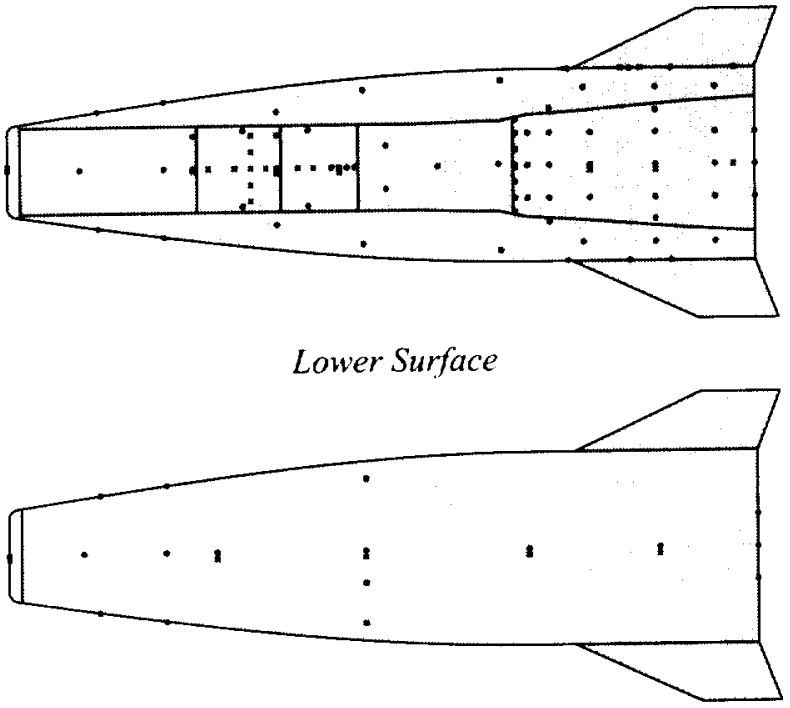

Upper Surface

Figure 18. Pressure transducer and thermocouple layout on the $X-43 \mathrm{~A}$.

\section{Summary}

An overview has been provided outlining the methods which have been, and continue to be, utilized in the development of the preflight aerodynamic database for the Hyper-X flight experiments. In order to develop the aerodynamic database to support the three Hyper-X flight tests, an extensive wind tunnel test program has been executed. These wind tunnel tests have provided basic aerodynamic force and moment data, boundary layer trip designs, and forebody pressure distribution data over the range of anticipated flight Mach numbers for the Hyper$\mathrm{X}$ flight profiles. In addition to wind tunnel test efforts, various state-of-the-art CFD codes have been utilized to assess the launch vehicle and stage separation aerodynamics, and the effects of powered scramjet operation and the influence of the propulsion generated flowfield on the overall X-43A vehicle aerodynamics. A brief description of several of the key aerodynamic characteristics of the X-43A at or near the scramjet operation test point has also been provided. The configuration is statically stable in three axes at the design test conditions, and has adequate control power provided by the all-moving horizontal tails and the vertical tail-rudder surfaces. The airframe integrated scramjet engine operation has a substantial effect on the X-43A longitudinal trim control requirements, and an indirect effect on the lateral-directional characteristics due to the same longitudinal control deflection variations. Both the vehicle's longitudinal stability and the rudder lateral-directional control effectiveness are diminished with increased angle-of- attack beyond about eight degrees. The current schedule calls for the first Mach 7 Hyper-X flight test to fly in the fall of 2000 . The data that will be collected during this first test, and the subsequent Mach 7 and 10 tests, will be utilized to validate and verify the preflight design and prediction methods, providing for continued advancement of the state-of-the-art in hypersonic vehicle integrated propulsion system-airframe aerodynamics.

\section{References}

1. Rausch, V. L., McClinton, C. R., Hicks, J. W.: "NASA Scramjet Flight to Breath New Life into Hypersonics," Aerospace America, July 1997.

2. Schweikart, L.: The Hypersonic Revolution: Case Studies in the History of Hypersonic Technology. Volume III - The Quest for the Orbital Jet: The National Aero-Space Plane Program (1983 - 1995). Air Force History and Museums Program, Bolling AFB, D. C., 1998.

3. Scramjet Propulsion (Chapter 5, Appendix B: NASA 's Hyper-X Program), Edited by Dr. T. Curran and Dr. S.N.B. Murthy, AIAA Progress In Astronautics and Aeronautics Series, Vol. TBD, 2000.

4. Rausch, V. L., McClinton, C. R., Crawford, L.: "Hyper-X: Flight Validation of Hypersonic Airbreathing Technology," ISABE Paper 97-7024, Sept. 1997.

5. McClinton, C. R: "Hyper-X Propulsion," University of Tennessee Space Institute Hypersonics Short Course notes, April, 2000.

6. Hunt, J. L., Eiswirth, E. A.: "NASA's Dual-Fuel Airbreathing Hypersonic Vehicle Study," AIAA CP96-4591, Presented at the $7^{\text {th }}$ International Space Planes and Hypersonics Systems \& Technology Conference, Nov. 1996.

7. Bogar, T. J., Alberico, J. F., Johnson, D. B., Espinosa, A. M., Lockwood, M. K.: "Dual-Fuel Lifting Body Configuration Development," AIAA CP 96-4592, Presented at the $7^{\text {th }}$ International Space Planes and Hypersonics Systems \& Technology Conference, Nov. 1996.

8. Air Launched Flight Experiment Final Report. McDonnell Douglas Aerospace, June 1995. 

9. Voland, R. T., Rock, K. E., Huebner, L. D., Witte, D. W., Fisher, K. E., and McClinton, C. R.: "Hyper$\mathrm{X}$ Engine Design and Ground Test Program," AIAA 98-1532, Presented at the $8^{\text {th }}$ International Space Planes and Hypersonics Systems \& Technology Conference, April 1998, Norfolk, VA.

10. Reubush, D. E.: "Hyper-X Stage SeparationBackground and Status," AIAA 99-4818, Presented at the AIAA 9th International Space Planes and Hypersonic Systems and Technologies Conference, Norfolk, Virginia, Nov. 1999.

11. McClinton, C. R., Voland, R. T., Holland, S. D., Engelund, W. C., White, J. T., Pahle, J. W.: "Wind Tunnel Testing, Flight Scaling and Flight Validation with Hyper-X," AIAA 98-2866, presented at the $20^{\text {th }}$ AIAA Advanced Measurement and Ground Testing Technology Conference, June 1998, Albuquerque, NM.

12. Huebner, L. D., Rock, K. E., Witte, D. W., Ruf, E. G., and Andrews, E. H, Jr.: "Hyper-X Engine Testing in the NASA Langley 8-Foot High Temperature Tunnel." AIAA 2000-3605, presented at the 36th AIAA/ASME/SAE/ASEE Joint Propulsion Conference, Huntsville, AL, July, 2000.

13. Rovner, D.: "GN\&C for Pegasus Air Launched Space Booster: Design and First Flight Results," AIAA CP 91-1105, 1991

14. Allen, V.: "Hyper-X Launch Vehicle Aerodynamics Development," AIAA 2000-4007, Presented at the $18^{\text {th }}$ AIAA Applied Aerodynamics Conference, Denver, CO, Aug., 2000.

15. Woods, W. C., Holland, S. D.: "Hyper-X Stage Separation Wind Tunnel Test Program," AIAA 2000-4008, Presented at the $18^{\text {th }}$ AIAA Applied Aerodynamics Conference, Denver, CO, Aug., 2000.

16. Buning, P. G., Wong, T. C., Dilley, A. D., and Pao, J. L.: "Prediction of Hyper-X Stage Separation Aerodynamics using CFD," AlAA 2000-4009, Presented at the $18^{\text {th }}$ AIAA Applied Aerodynamics Conference, Denver, CO, Aug., 2000.
17. Heiser, W. H., and Pratt, D. T.: Hypersonic Airbreathing Propulsion, AIAA Education Series, AIAA, Inc., Washington, D. C., 1994.

18. Holland, S. D., Woods, W. C., and Engelund, W. C.: "Hyper-X Research Vehicle (HXRV) Experimental Aerodynamics Test Program Overview," AIAA2000-4011, Presented at the $18^{\text {th }}$ AIAA Applied Aerodynamics Conference, Denver, CO, Aug., 2000 .

19. Huebner, L. D., and Tatum, K. E.: "CFD Code Calibration and Inlet-Fairing Effects on a 3D Hypersonic Powered-Simulation Model," AIAA 933041 , July 1993.

20. Cockrell, C. E., Jr., Engelund, W. C., Bittner, R. D., Dilley, A. D., Jentink, T. N., and Frendi, A.: "Integrated Aero-Propulsive CFD Methodology for the Hyper-X Flight Experiment," AIAA-2000-40 I0, Presented at the $18^{\text {th }}$ AIAA Applied Aerodynamics Conference, Denver, CO, Aug., 2000.

21. Berry, S. A., Auslander A. H., and Dilley, A. D.: "Hypersonic Boundary Layer Trip Development for Hyper-X," AIAA-2000-4012, Presented at the $18^{\text {th }}$ AIAA Applied Aerodynamics Conference, Denver, CO, Aug., 2000.

22. White, J. T.: "X-43A Real Time Angle-of-Attack Estimation Scheme Utilizing Flush Airdata Sensing (FADS) System Inputs," AIAA-2000-4013, Presented at the $18^{\text {th }}$ AIAA Applied Aerodynamics Conference, Denver, CO, Aug., 2000.

23. Morelli, E., and Klein, V., "Optimal Input Design for Aircraft Parameter Estimation Using Dynamic Programming Principles," AIAA 90-2801, Aug. 1990.

24. Illif, K. W, Maine, R. E., and Montgomery, T. D., "Important Factors in the Maximum Likelihood Analysis of Flight Test Maneuvers," NASA TP 1459, Jan. 1979. 


\section{NASA STI Acquisitions DAA Authorization}

The following papers (copies enclosed) have been DAA approved as Unclassified, Publicly Available documents:

\section{Meeting Presentations:}

AIAA Atmospheric Flight Mech. Conf. \& Exhibit, 8/14-17/2000, Denver, CO:

M. Croom, et al.: Research on the F/A-18E/F Using a 22\%-Dynamically-Scaled Drop...

Fluids 2000, 6/19-22/2000, Denver, CO:

A. Seifert, et al.: Separation Control at Flight Reynolds Numbers: Lessons Learned...

Guidance, Navigation \& Control Conf. \& Exhibit, 8/14-7/2000, Denver, CO:

D. M. Elliott, et al.: NASA Research for Instrument Approaches to Closely Spaced...

J. L. Roger: A Parallel Approach to Optimum Actuator Selection With a Genetic...

P. G. Maghami: Robustness of Flexible Systems With Component-Level...

18th Applied Aerodynamics Meeting, 8/14-17, 2000, Denver, CO:

C. L. Rumsey, et al.: Recent Turbulence Model Advances Applied to Multielement...

W. C. Engelund, et al: : Aerodynamic Database Development for the Hyper-X...

P. G. Buning, et al.: Prediction of Hyper-X Stage Separation Areodynamics...

C. E. Cockrell, Jr., et al.: Integrated Aero-Propulsive CFD Methodology for the...

11 th Thermal and Fluids Analysis Workshop, 8/21-25/2000, Cleveland, OH:

R. M. Amundsen, et al.: Thermal Analysis Methods for an Earth Entry Vehicle

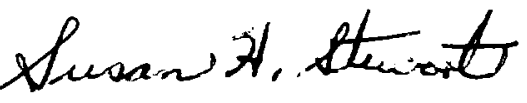

Susan H. Stewart

DAA Representative

NASA Langley Research Center

Mail Stop 196

Hampton, VA 23681-2199 s.h.stewart@larc.nasa.gov

phone: (757) 864-2518

fax: (757) 864-2375 


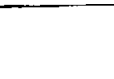

.... 